\title{
Digital Elevation Model of King Edward VII Peninsula, West Antarctica, From SAR Interferometry and ICESat Laser Altimetry
}

\author{
Sangho Baek, Oh-Ig Kwoun, Alexander Braun, Zhong Lu, and C. K. Shum
}

\begin{abstract}
We present a digital elevation model (DEM) of King Edward VII Peninsula, Sulzberger Bay, West Antarctica, developed using 12 European Remote Sensing (ERS) synthetic aperture radar (SAR) scenes and 24 Ice, Cloud, and land Elevation Satellite (ICESat) laser altimetry profiles. We employ differential interferograms from the ERS tandem mission SAR scenes acquired in the austral fall of 1996, and four selected ICESat laser altimetry profiles acquired in the austral fall of 2004, as ground control points (GCPs) to construct an improved geocentric 60-m resolution DEM over the grounded ice region. We then extend the DEM to include two ice shelves using ICESat profiles via Kriging. Twenty additional ICESat profiles acquired in 2003-2004 are used to assess the accuracy of the DEM. After accounting for radar penetration depth and predicted surface changes, including effects due to ice mass balance, solid Earth tides, and glacial isostatic adjustment, in part to account for the eight-year data acquisition discrepancy, the resulting difference between the DEM and ICESat profiles is $-0.57 \pm 5.88 \mathrm{~m}$. After removing the discrepancy between the DEM and ICESat profiles for a final combined DEM using a bicubic spline, the overall difference is $0.05 \pm 1.35 \mathrm{~m}$.
\end{abstract}

Index Terms-Glaciology, Ice, Cloud, and land Elevation Satellite (ICESat), snow and ice, space geodetic surveys, synthetic aperture radar (SAR).

\section{INTRODUCTION}

$\mathbf{T}$ HE USE of synthetic aperture radar interferometry (InSAR) is an effective means for studying the ice mass balance of polar regions and its contribution to global sea level change [1]. An accurate, high-resolution digital elevation model (DEM) referenced within a well-defined terrestrial reference frame (TRF) is an inherent requirement to facilitate the use of InSAR to conduct these studies in remote polar regions.

King Edward VII Peninsula is located at $76.5^{\circ} \mathrm{S}$ to $77.5^{\circ} \mathrm{S}$ and $153^{\circ} \mathrm{W}$ to $156^{\circ} \mathrm{W}$ by Sulzberger Bay, West Antarctica. The best DEMs currently available in the study area include The Ohio State University Byrd Polar Research Center (BPRC) DEM generated using European Remote Sensing 1 satellite (ERS-1) ice

Manuscript received February 8, 2005; revised June 16, 2005. This research was supported in part by the Office of Polar Programs, National Science Foundation under Grant OPP-0088029 and in part by the U.S. Geological Survey Land Remote Sensing Program.

S. Baek and C. K. Shum are at the Laboratory for Space Geodesy and Remote Sensing, The Ohio State University, Columbus, OH 43210 USA (e-mail: ckshum@osu.edu).

O.-I. Kwoun and Z. Lu are at the Science Applications International Corporation, U.S. Geological Survey National Center, Earth Resources Observation System Data Center, Sioux Falls, SD 57198 USA.

A. Braun is with the Department of Geomatics Engineering, University of Calgary, Calgary, AB, T2N 1N4 Canada.

Digital Object Identifier 10.1109/LGRS.2005.853623 mode radar altimetry and other data [2] and the 200-m resolution BPRC Radarsat Mapping Project (RAMP) DEM generated using ERS-1 altimetry, airborne survey, and the Antarctic Digital Database (ADD) data [3]. Our attempt to use the RAMP DEM to correct the topographic effect for repeat-pass InSAR studies of ice stream velocities, tidal dynamics, and grounding line migrations over the Sulzberger Ice Shelf region [4] was unsuccessful due primarily to the coarse resolution in the model and provided motivation to create an improved DEM for this region.

InSAR has proven to be an excellent tool to derive DEMs with high spatial resolution [5]. However, the estimation of ice topography using InSAR has always been a challenge because accurate ground control points (GCPs) to refine baseline estimation and tie the DEM to the vertical datum are often unavailable. Extreme weather conditions and logistic difficulties in Antarctica are among the barriers to collecting necessary GCPs by ground survey for InSAR studies. Therefore, a multisensor approach was sought from previous studies (see [6]) using radar altimetry data as GCPs. In this study, we exploit satellite laser altimetry data as GCPs in InSAR processing.

In this letter, the DEM is defined as geocentrically referenced to a terrestrial reference frame (TRF). In this study, the International TRFs (ITRFs) to which the ERS and the Ice, Cloud, and land Elevation Satellite (ICESat) precise orbits are referenced, namely ITRF95 and ITRF2000, are used, respectively. In the context of the DEM study, both ITRF systems have practically the same accuracy for the InSAR and ICESat altimetry analyses. We demonstrate the generation of an accurate (meters) and high-resolution (60-m) DEM over grounded ice and floating ice shelves using laser altimetry profiles acquired by the ICESat, eliminating the need for in situ GCPs.

\section{DATASETS}

\section{A. SAR Data}

For this study, six ERS-1/2 SAR tandem mission data pairs acquired in 1996 are used (Table I). The three-day, repeat-pass ERS-1 SAR data are unavailable for the study region. Several 35-day, repeat-pass data are available; however, the temporal decorrelation was too significant to use these data for repeatpass interferometry.

For the six tandem interferograms for this study, the perpendicular baseline $\mathrm{B}_{\mathrm{p}}$, which is the baseline perpendicular to the line of sight, varies from -5.8 to $-194 \mathrm{~m}$. The coherence is estimated within a $5 \times 5$ moving window in a $3 \times 15$ multilooked 
TABLE I

ERS-1/2 TANDEM Mission Data USED IN This STUdy (All AsCEnding Passes)

\begin{tabular}{ccccc}
\hline \hline Track & $\begin{array}{c}\text { Orbits } \\
(\text { ERS-1/-2 })\end{array}$ & $\begin{array}{c}\text { Acquisition } \\
\text { Dates }\end{array}$ & $\mathrm{B}_{\mathrm{p}}{ }^{\mathrm{a}}, \mathrm{m}$ & $\begin{array}{c}\text { Mean } \\
\text { Coherence }\end{array}$ \\
\hline \multirow{3}{*}{381} & $23916 / 4243$ & 10/11 Feb 1996 & -152.1 & 0.41 \\
\cline { 2 - 5 } & $24417 / 4744$ & 16/17 Mar 1996 & -147.4 & 0.40 \\
\cline { 2 - 5 } & $24918 / 5245$ & 20/21 Apr 1996 & -5.8 & 0.66 \\
\hline \multirow{3}{*}{424} & $23959 / 4286$ & 13/14 Feb 1996 & -120.8 & 0.50 \\
\cline { 2 - 5 } & $24460 / 4787$ & 19/20 Mar 1996 & -194.9 & 0.40 \\
\cline { 2 - 5 } & $24961 / 5288$ & 23/24 Apr 1996 & -22.9 & 0.62 \\
\hline \hline
\end{tabular}

${ }^{\mathrm{a}} \mathrm{B}_{\mathrm{p}}:$ Perpendicular baseline.

interferogram, and the mean coherence value for each interferogram ranges from $0.40-0.66$ (Table I).

\section{B. ICESat Data}

On January 12, 2003, the National Aeronautics and Space Administration launched the first Earth observing satellite laser altimetry mission, ICESat. ICESat's laser footprint is about 70 $\mathrm{m}$ in diameter. Its along-track spacing of $170 \mathrm{~m}$ provides much denser and more accurate elevation data than traditional radar altimetry, and ICESat works well over all surface types with moderate slopes. The vertical accuracy of ICESat laser altimetry over the ice sheet is projected to be approximately $5 \mathrm{~cm} \mathrm{rms}$, and the horizontal footprint accuracy is within $\pm 10 \mathrm{~m}$ [7]. Initial studies have shown that ICESat elevation data are accurate to within $\pm 10 \mathrm{~cm}$ [8], [9].

In this study, the Geoscience Laser Altimeter System (GLAS) data products, GLA06 (global elevations) and GLA12 (ice sheet elevations), available through the National Snow and Ice Data Center [10], are used. These data products include a total of 24 profiles from the ICESat laser phases 2a (September 25, 2003 through November 19, 2003), 2b (February 17, 2004 through March 21, 2004), and 2c (May 17, 2004 through June 19, 2004).

\section{DEM GENERATION}

The four-pass differential InSAR technique developed in [6], [11], and [12] is adopted in this study. Data processing includes the following steps: image coregistration, differential interferogram generation and phase noise filtering, phase unwrapping, baseline refinement, and phase-to-height transformation. The differential interferograms are obtained by double differencing of the tandem interferograms (Fig. 1). Next, the floating ice shelves and the ocean area including the grounding zone from the combined interferogram are masked out to first generate land-only DEM. For the phase unwrapping, we use the branch cut algorithm [13] built in the GAMMA InSAR software [14]. The accurate baseline estimation is critical to the DEM fidelity due to the proportional relationship between the interferometric phase and perpendicular baseline. Therefore, subsequent processing is conducted to refine the baselines. The baseline is modeled as varying linearly along-track using only orbital vectors. Next, to refine the baseline, GCPs with known elevations in the image can be used [15]. In this study, selected ICESat profiles are used as GCPs; four ICESat profiles obtained during the same season (February-March 2004) as SAR data acquisition
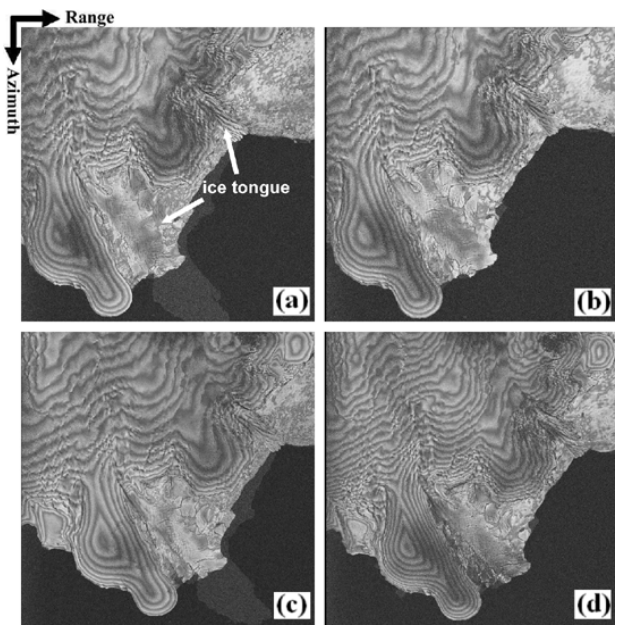

Fig. 1. Differential interferograms from image ID $1-4$ of Table II.

TABLE II

DIFFERENTIAL INTERFEROGRAM PAIRS

\begin{tabular}{cccccc}
\hline \hline $\begin{array}{c}\text { Image } \\
\text { ID }\end{array}$ & $\begin{array}{c}\text { Master pair } \\
\text { (ERS-1/-2) }\end{array}$ & $\begin{array}{c}\text { Slave pair } \\
(\text { ERS-1/-2) }\end{array}$ & $\begin{array}{c}\mathrm{B}_{\mathrm{p}} \\
\mathrm{m}\end{array}$ & $\begin{array}{c}\text { Phase } \\
\text { Error, deg }\end{array}$ & $\begin{array}{c}\text { Height } \\
\text { Error, m }\end{array}$ \\
\hline \hline 1 & $23916 / 4243$ & $24918 / 5245$ & -146.2 & 20.67 & 3.83 \\
\hline 2 & $24417 / 4744$ & $24918 / 5245$ & -141.6 & 21.16 & 4.05 \\
\hline 3 & $23959 / 4286$ & $24961 / 5288$ & -143.8 & 17.74 & 3.34 \\
\hline 4 & $24460 / 4787$ & $24961 / 5288$ & -217.8 & 21.65 & 2.69 \\
\hline \hline
\end{tabular}

time are selected. The baseline components, azimuth convergence rate, and constant phase are estimated using a nonlinear least squares adjustment. Cross-track azimuth convergence rates in the four differential interferogram pairs corresponding to the image pairs 1-4 in Table II are 0.11, 0.08, 0.04, and $0.12 \mathrm{~m} / \mathrm{s}$, respectively. The corresponding baseline length changes in the cross-track before and after the baseline refinements are 1.02, $0.21,0.22$, and $0.19 \mathrm{~m}$. Table II also shows the perpendicular baseline $\mathrm{B}_{\mathrm{p}}$ and estimated phase and height errors for the four generated differential interferograms. Based on the refined baselines, a DEM for each differential interferogram pair is generated. For the four differential interferograms, the averaged phase error from Cramer-Rao bound [16] ranges from $17.74^{\circ}$ to $21.65^{\circ}$ with the equivalent number of looks of 24 [15]. The resulting averaged height error [17] falls between 2.69 and $4.05 \mathrm{~m}$. It should be noted that these values indicate the lower bound of the phase and height errors.

Four InSAR DEMs are generated out of six tandem pairs [Fig. 1(a)-(d) and Table II] and are averaged with the same weight to first generate a land-only DEM. To generate the DEM over the floating ice shelf, the land-only DEM is combined with the four ICESat profiles passing over the two major ice tongues (approximately $32 \mathrm{~km} \times 32 \mathrm{~km}$ and $20 \mathrm{~km} \times 20 \mathrm{~km}$ ) using Kriging. Generation of such a DEM bordering grounding zones will be critical in the study of grounding line migration, tidal dynamics, and ice stream velocities. Despite the rapidly changing atmosphere conditions of Antarctica, due to the lack of meteorological data over the region, the (differenced) effects of (wet and dry) tropospheric and ionospheric delays for the radar signal are ignored. However, given that Antarctica is 
TABLE III

Four ICESAT PROFILES USED FOR GCPS AND THEIR HEIGHT DIFFERENCES WITH THE INSAR DEM

\begin{tabular}{cccc}
\hline \hline $\begin{array}{c}\text { Profile } \\
\text { ID }\end{array}$ & $\begin{array}{c}\text { ICESat } \\
\text { Profile }\end{array}$ & $\begin{array}{c}\text { Length } \\
\mathrm{km}\end{array}$ & $\begin{array}{c}\text { Mean } \pm \text { Standard deviations } \\
\mathrm{m}\end{array}$ \\
\hline $\mathrm{A}$ & 17 Feb 2004 & 62.3 & $2.93 \pm 3.57$ \\
\hline $\mathrm{B}$ & 18 Feb 2004 & 30.2 & $2.33 \pm 4.26$ \\
\hline $\mathrm{C}$ & 12 Mar 2004 & 56.6 & $-0.23 \pm 4.55$ \\
\hline $\mathrm{D}$ & 13 Mar 2004 & 54.4 & $-2.26 \pm 5.50$ \\
\hline \hline
\end{tabular}

TABLE IV

ERROR SOURCES

\begin{tabular}{ccc}
\hline \hline Error Source & $\begin{array}{l}\text { Changes } \\
(8 \text { years })\end{array}$ & Reference \\
\hline Ice melt/flow, Snow accumulation & -6 to $-50 \mathrm{~cm}$ & {$[19]$} \\
\hline Radar penetration & $>\sim 10 \mathrm{~m}$ & {$[20],[21]$} \\
\hline \hline
\end{tabular}

relatively dry, one can expect that the localized wet tropospheric delay differences would be minimal. The averaging of four DEMs would further reduce such atmospheric delay errors in the radar signal. Azimuth streaks [18] have not been observed in our images, which suggests that there are no severe ionospheric disturbances on the SAR data acquisition days.

\section{VALIDATION OF THE DEM}

In addition to the four ICESat profiles used for GCPs in InSAR processing, we use 20 independent profiles to assess the accuracy of the resulting InSAR DEM. Table III shows the four ICESat GCP profiles and their comparisons with the InSAR DEM. The difference between all 24 ICESat profiles and the InSAR DEM is $-0.57 \pm 5.88 \mathrm{~m}$.

The differences can be attributed to a number of factors listed in Table IV. In addition to the previously mentioned assumption that the atmospheric delay anomalies are negligible in differential InSAR processing, other physical processes and error sources exist when combining 1996 SAR data and 2004 ICESat laser altimetry data to derive a DEM. First, the processes include surface changes or ice dynamics such as ice melt, snow accumulation, and ice flow. [19] reported that the average elevation change in the Sulzberger Ice Shelf drainage basin has a rate of $-3.3 \pm 2.6 \mathrm{~cm} /$ year between 1992 and 1996. If this rate persists to the present day, the cumulative elevation change over eight years (1996-2004) could be in the range of -6 to $-50 \mathrm{~cm}$. Second, laser altimetry measures the surface of snow/ice, while radar (SAR) penetrates into the snow/ice cover. The depth of radar penetration depends on the wetness and compactness of the ice/snow cover, and it can reach a few tens of meters in C-band radar [20], [21]. In addition to the above-mentioned error sources, other relatively smaller effects, which include deformations due to glacial isostatic adjustment, solid Earth tides, and atmosphere loading, have a combined magnitude of only several centimeters or less. In summary, despite all these potential error sources, in part resulting from eight years of measurement acquisition time difference, the overall difference of $-0.57 \pm 5.88 \mathrm{~m}$ between ICESat profiles and InSAR DEM indicates an excellent agreement.
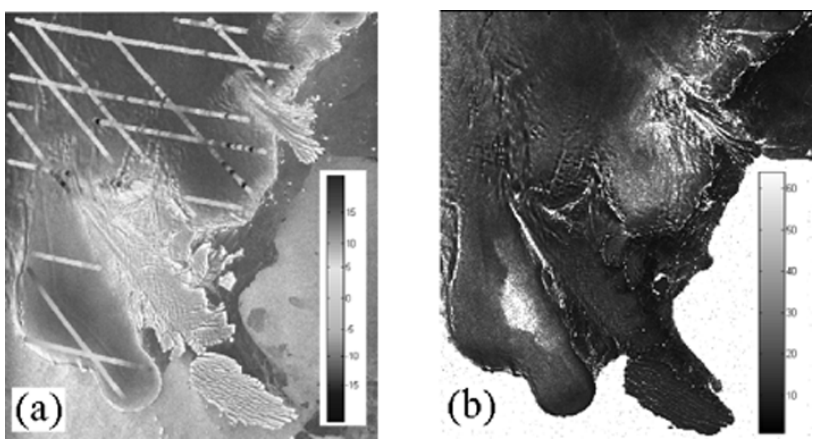

Fig. 2. (a) Elevation difference, ICESat-InSAR in meters, draped on a SAR amplitude image before adjustment in image coordinate. (b) Phase error in degrees in the interferogram between ERS-1 orbit 23916 and ERS-2 orbit 4243.

TABLE V

VALIDATIONS OF ICESAT PROFILES With THE INSAR DEM, BEFore AND AfTer AdJustment of THE DEM to Selected ICESAT PROFILES USING BICUBIC SPLINE

\begin{tabular}{ccccc}
\hline \hline \multirow{2}{*}{$\begin{array}{c}\text { Validation } \\
\text { Profiles }\end{array}$} & \multirow{2}{*}{$\begin{array}{c}\text { Before } \\
\text { Adjustment, } \mathrm{m}\end{array}$} & \multicolumn{3}{c}{$\begin{array}{c}\text { DEM differences with } \\
\text { validation ICESat profiles, } \mathrm{m}\end{array}$} \\
\cline { 3 - 5 } & & $2 \mathrm{a}$ & $2 \mathrm{~b} / \mathrm{c}$ & All \\
\hline $2 \mathrm{a}$ & $0.11 \pm 6.14$ & $-0.07 \pm 1.15$ & $-0.09 \pm 3.44$ & $-0.14 \pm 1.25$ \\
\hline $2 \mathrm{~b} / \mathrm{c}$ & $-1.13 \pm 5.48$ & $-0.05 \pm 3.21$ & $-0.01 \pm 1.17$ & $0.02 \pm 1.26$ \\
\hline All & $-0.57 \pm 5.88$ & - & - & $0.05 \pm 1.35$ \\
\hline \hline
\end{tabular}

However, Fig. 2(a) shows the localized errors in some areas of the DEM [also, see the height difference profile before adjustment in Fig. 4(a)]. The actual surface change between SAR and ICESat data acquisitions and radar penetration depth variation are the most likely sources of the phase error for this area. In Fig. 2(b), the cape in the lower left corner of the image shows higher phase errors (bright colored) than other areas; this implies that there may be significant variation in backscattering characteristics in the area, supporting the possibility of spatial variation in the depth of radar penetration. The baseline refinement through GCPs is to eliminate the overall (systematic) error trend in the image. To eliminate the local errors remaining even after the baseline refinement, we apply further adjustment.

For the adjustment, the InSAR DEM is selectively compared with the same-season ICESat elevation profiles and is adjusted according to the differences. First, ICESat data from February-March and May-June 2004 (phases 2b and 2c, respectively) are used as reference data to derive difference profiles with respect to the DEM. These differenced profiles are gridded to derive a difference surface model using a bicubic spline. This surface model is applied to the DEM in order to adjust it to the ICESat profiles of phases $2 b$ and $2 c$. Then, the differences between ICESat data from September-November 2003 (phase 2a) and the adjusted DEM are computed. For this same-season adjustment, the differences between adjusted DEM and ICESat data of phase $2 \mathrm{~b} / \mathrm{c}$ and $2 \mathrm{a}$ are $-0.01 \pm 1.17 \mathrm{~m}$ and $-0.09 \pm 3.44 \mathrm{~m}$, respectively (Table V, fourth column). The opposite-season adjustment is then performed. ICESat phase $2 \mathrm{a}$ data are used as reference profiles to compute an opposite-season adjusted DEM. The differences between this DEM and ICESat profiles from phase $2 \mathrm{~b} / \mathrm{c}$ are computed. Here, the differences are $-0.07 \pm 1.15 \mathrm{~m}$ and $-0.05 \pm 3.21 \mathrm{~m}$ for $2 \mathrm{a}$ and $2 \mathrm{~b} / \mathrm{c}$, respectively (Table V, third column). In both cases, the surface adjustment 


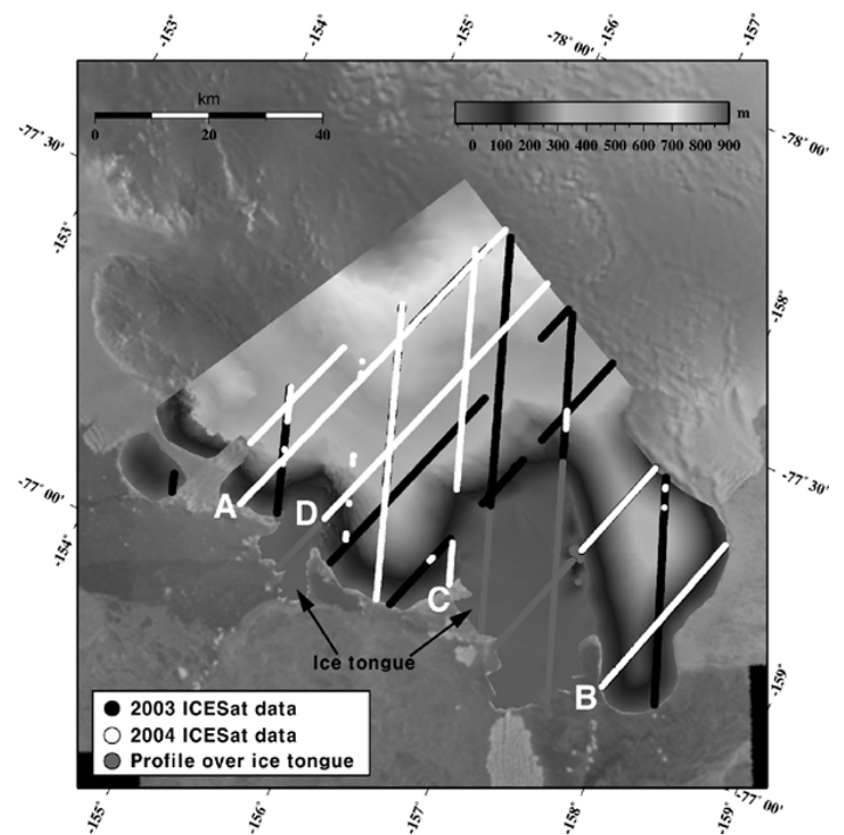

Fig. 3. Adjusted InSAR DEM and ICESat tracks draped on the radarsat mosaic image in gray. ICESat profiles from 2003 (phase 2a) are in black, and profiles from 2004 (phase $2 \mathrm{~b} / \mathrm{c}$ ) are in white. Profiles over ice tongue are indicated in gray. Four ICESat GCP profiles in white are indicated by A-D.

leads to significantly smaller mean differences and standard deviations for both phases $2 \mathrm{~b} / \mathrm{c}$ and $2 \mathrm{a}$ with respect to the original DEM (Table V, second column). These comparisons reveal localized residual elevation discrepancies between the InSAR DEM and the ICESat altimetry profiles. While the origin of these offsets is speculated to be partially due to radar penetration, all the ICESat data are used to create an InSAR/altimetry composite DEM by removing these localized elevation discrepancies using a bicubic spline. As a result, the difference between ICESat elevations and the adjusted (composite) DEM is $0.05 \pm 1.35 \mathrm{~m}$ (Table V, fifth column).

Fig. 3 shows the resulting DEM including the grounded ice and the two floating ice shelves, and the ICESat tracks of phases $2 \mathrm{a}, 2 \mathrm{~b}$, and 2c with the RAMP mosaic image [22] in the background. The final DEM is compared to ICESat profiles, and RAMP DEM in Fig. 4(a)-(c) represents the height differences between the original and the composite DEMs and all 24 ICESat profiles available in the study region.

\section{CONCLUSION}

In this study, a high-resolution (60-m) DEM for King Edward VII Peninsula, Sulzberger Bay, West Antarctica, is generated using differential SAR interferometry over grounded ice and Kriging method on floating ice shelves. Satellite laser altimeter data from ICESat are used as GCPs in generating the InSAR-based DEM. We conclude that the differential InSAR technique incorporated with ICESat laser altimeter data is a cost-effective method for generating DEMs in remote areas like Antarctica and for cases where GCPs are unavailable. The derived DEM can be used for ice surface deformation studies, tidal dynamics, ice shelf grounding line detection, and estimation of grounding zone topography. We show that InSAR and ICESat data are complementary data that form the basis for generation (a) 18 Feb 2004

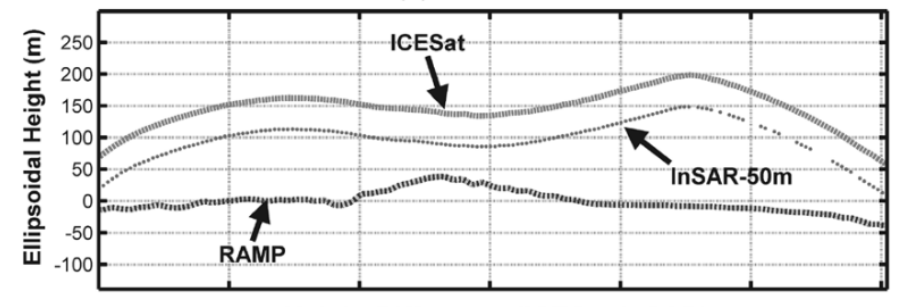

Height Difference (ICESat-InSAR)

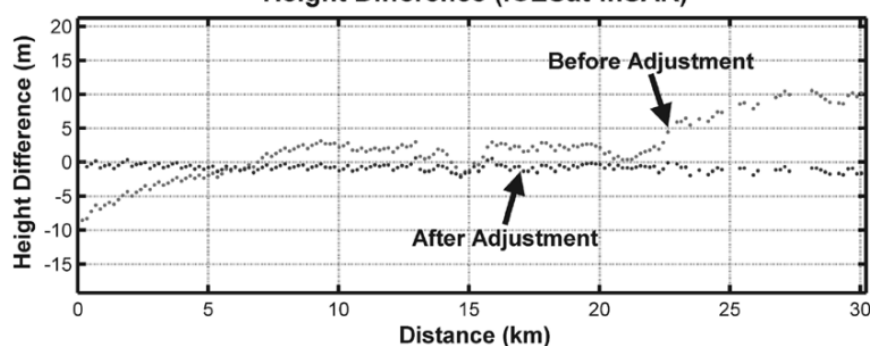

(b) 13 Mar 2004
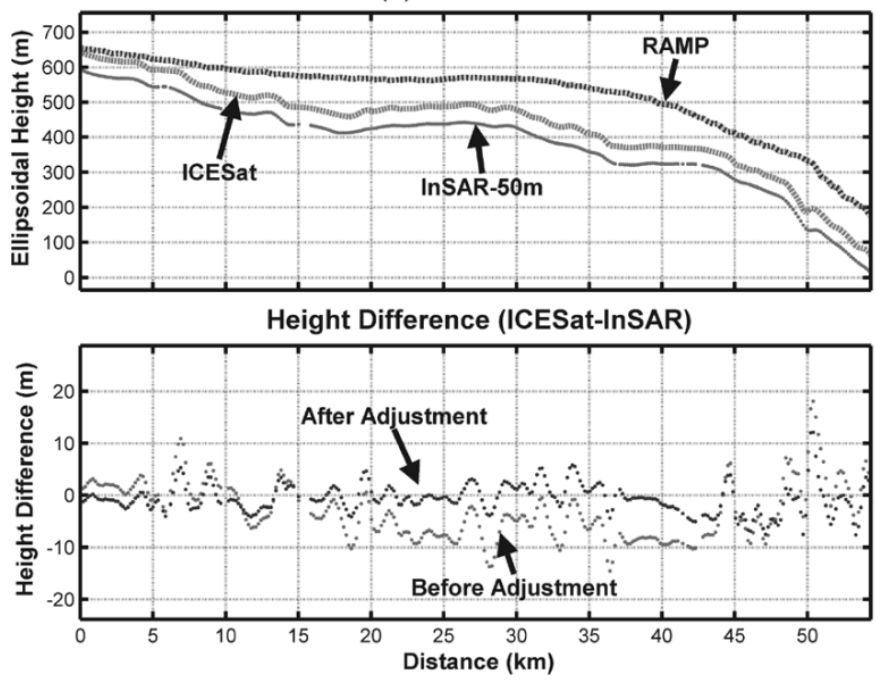

(c) Height Difference(ICESat-InSAR DEM) on all profiles

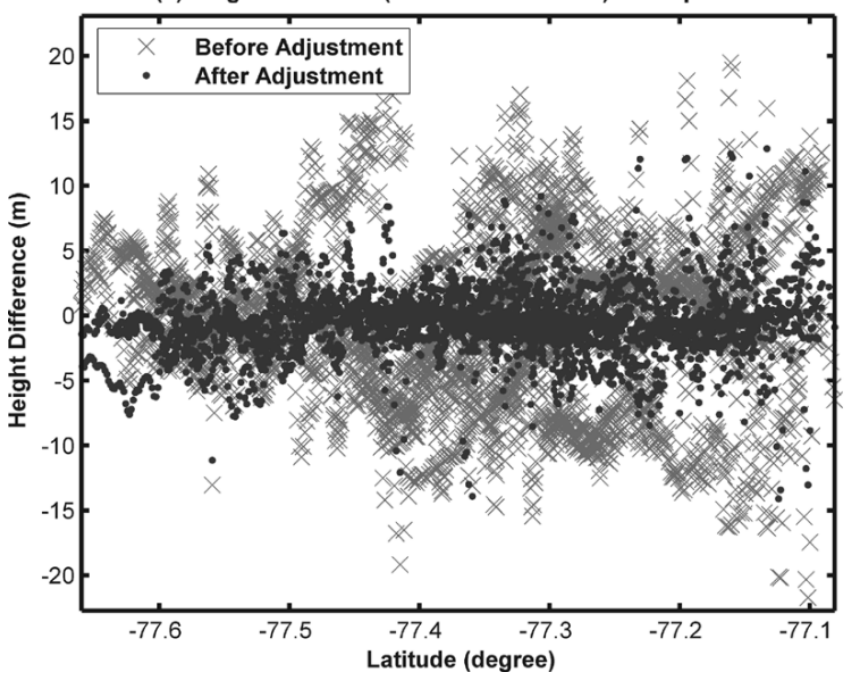

Fig. 4. Elevation comparison among ICESat, adjusted InSAR DEM, and RAMP DEM profiles on (a) February 18, 2004 and on (b) March 13, 2004, and (c) the height difference between ICESat profiles and InSAR DEM before and after adjustment over all 24 profiles.

of accurate (several meters) and high-resolution (60-m) DEM in Antarctica. 


\section{ACKNOWLEDGMENT}

ERS-1/2 SAR data are copyrighted by the European Space Agency (ESA) and were provided by the Alaskan Satellite Facility. ICESat data were provided by the National Snow and Ice Data Center (NSIDC), Boulder, CO, and processed by NASA Goddard Space Flight Center and the ICESat Project. The authors acknowledge B. Csatho (Byrd Polar Research Center of The Ohio State University), K. Barbieri (Raytheon), and the NASA Goddard Space Flight Center ICESat Project for their support in ICESat data processing, and C. Werner of GAMMA for his help in InSAR processing.

\section{REFERENCES}

[1] E. Rignot and R. Thomas, "Mass balance of the polar ice sheets," Science, vol. 297, pp. 1502-1506, 2002.

[2] H. Liu, K. C. Jezek, and B. Li, "Development of an antarctic digital elevation model by integrating cartographic and remotely sensed data: A geographic information system based approach," J. Geophys. Res., vol. 104 , no. B10, pp. 23,199-23 213, 1999.

[3] H. Liu, K. C. Jezek, B. Li, and Z. Zhao, "Radarsat Antarctic Mapping Project digital elevation model, version 2," Nat. Snow and Ice Data Center, Boulder, CO, 2001.

[4] C. Shum, Y. Yi, Y. Wang, S. Baek, O. Andersen, and Z. Lu, "Ross sea tide modeling using InSAR and radar altimetry," EOS Trans. AGU, vol. 83 , no. 47, 2002.

[5] S. Hensley, R. Munjy, and P. Rosen, "Interferometric synthetic aperture radar (IFSAR)," in Digital Elevation Model Technologies and Applications: The DEM Users Manual, D. F. Maune, Ed. Bethesda, MD: Amer. Soc. Photogramm. Remote Sens., 2001, pp. 143-206.

[6] I. Joughin, D. Winebrenner, M. Fahnestock, R. Kwok, and W. Krabill, "Measurement of ice-sheet topography using satellite radar interferometry," J. Glaciol., vol. 42, pp. 10-22, 1996.

[7] H. J. Zwally and C. Shuman, "ICESat: Ice, Cloud, and land Elevation Satellite," NASA GSFC, Greenbelt, MD, Brochure FS-2002-9-047-GSFC, 2002.

[8] A. Braun, K. Cheng, B. Csatho, and C. Shum, "ICESat laser altimetry in the great lakes," presented at the Inst. Navigation (ION) 60th Annu. Meeting, Dayton, OH, 2004.
[9] L. A. Magruder, B. E. Schutz, and E. C. Silverberg, "Laser pointing angle and time of measurement verification of the ICESat laser altimeter using a ground-based electro-optical detection system," J. Geodesy, vol. 77, no. 3-4, pp. 148-154, 2003.

[10] H. J. Zwally et al., "GLAS/ICESat L2 Antarctic and Greenland ice sheet altimetry data V001," Nat. Snow and Ice Data Center, Boulder, CO, 2003.

[11] R. Kwok and M. A. Fahnestock, "Ice sheet motion and topography from radar interferometry," IEEE Trans. Geosci. Remote Sens., vol. 34, no. 1, pp. 189-200, Jan. 1996.

[12] D. R. Fatland and C. S. Lingle, "Analysis of the 1993-95 Bering Glacier (Alaska) surge using differential SAR interferometry," J. Glaciol., vol. 44, no. 148 , pp. 532-546, 1998.

[13] R. M. Goldstein, H. A. Zebker, and C. L. Werner, "Satellite radar interferometry: Two-dimensional phase unwrapping," Radio Sci., vol. 23, no. 4, pp. 713-720, 1988.

[14] C. L. Werner, U. Wegmüller, T. Strozzi, and A. Wiesmann, "GAMMA SAR and interferometry processing software," presented at the ERSENVISAT Symp., Gothenburg, Sweden, Oct. 16-20, 2000.

[15] A. Zebker, C. L. Werner, P. A. Rose, and S. Hensley, "Accuracy of topographic maps derived from ERS-1 interferometric radar," IEEE Trans. Geosci. Remote Sens., vol. 32, no. 4, pp. 823-836, Jul. 1994.

[16] E. Rodriguez and J. M. Martin, "Theory and design of interferometric synthetic aperture radars," Proc. Inst. Elect. Eng. F, vol. 139, no. 2, pp. 147-159, 1992.

[17] F. K. Li and R. M. Goldstein, "Studies of multibaseline spaceborne interferometric synthetic aperture radars," IEEE Trans. Geosci. Remote Sens., vol. 28, no. 1, pp. 88-97, Jan. 1990.

[18] A. L. Gray, K. Mattar, and G. Sofko, "Influence of ionospheric electron density fluctuations on satellite radar interferometry," Geophys. Res. Lett., vol. 27, no. 10, pp. 1451-1454, 2000.

[19] D. Wingham, A. Ridout, R. Scharroo, A. Arthern, and C. Shum, "Antarctic elevation change from 1992 to 1996," Science, vol. 282, pp. 456-458, 1998.

[20] E. Hoen and H. Zebker, "Penetration depths inferred from interferometric volume decorrelation observed over the Greenland ice sheet," IEEE Trans. Geosci. Remote Sens., vol. 38, no. 6, pp. 2571-2583, Nov. 2000.

[21] E. Rignot, K. Echelmeyer, and W. Krabill, "Penetration depth of interferometric synthetic-aperture radar signals in snow and ice," Geophys. Res. Lett., vol. 28, no. 18, pp. 3501-3504, 2001.

[22] K. C. Jezek, "RAMP AMM-1 SAR image mosaic of Antarctica," Alaska SAR Facility, Fairbanks, AK, 2002. 